\title{
Management of distal femur fractures with locking compression plate: a prospective study
}

\author{
Sridhar Reddy Konuganti ${ }^{*}$, Sreenath Rao Jakinapally ${ }^{2}$, Vennamaneni Pratish Rao ${ }^{3}$, \\ Sivaprasad Rapur ${ }^{4}$
}

\begin{abstract}
Department of Orthopedics, ${ }^{1}$ Maheshwara Medical College and Hospital, Chitkul (V), Patancheru, Medak, ${ }^{2}$ Maxcure Hospital, Sarovar Complex, Secretariat Road, Saifabad, ${ }^{3}$ Government Medical college and Hospital, Siddipet,

${ }^{4}$ Mediciti Institute of medical sciences, Ghanpur, Medchal, Telangana, India
\end{abstract}

Received: 17 January 2018

Revised: 05 February 2018

Accepted: 06 February 2018

\section{*Correspondence: \\ Dr. Sridhar Reddy Konuganti, \\ E-mail: sridhara983@gmail.com}

Copyright: $(\odot$ the author(s), publisher and licensee Medip Academy. This is an open-access article distributed under the terms of the Creative Commons Attribution Non-Commercial License, which permits unrestricted non-commercial use, distribution, and reproduction in any medium, provided the original work is properly cited.

\begin{abstract}
Background: Distal femur fractures need to be treated operatively to achieve optimal outcomes. Different types of internal fixation devices have been used but, the number of revisions for non-union, loss of reduction and implant failure has been high.

Methods: This prospective study reviewed 20 cases of distal femoral fractures surgically managed with distal femoral locking compression plate between December 2013 and December 2015 at Mediciti Institute of medical sciences, Ghanpur, Medchal, tertiary care referral and trauma centre. Fractures were categorized according to OTA classification by Muller.

Results: Highest number of patients was in their 3rd decade (25\%) 18 out of 20 patients had closed injury. Type A2 Muller's fracture was the most common fracture type 7 out of 20 patients (35\%). The mean follow up period in this study was 8 months. The average range of knee flexion achieved was about $109^{\circ}$. The mean score 81.75 points were rated using Neer's functional score (Max 100).

Conclusions: The locking compression plate is the treatment of choice in the management of comminuted distal femoral fractures especially Type A fractures where we have found higher Neer scores. It may not completely solve the age-old problems associated with any fracture like non-union and malunion, but is valuable in the management of these fractures.
\end{abstract}

Keywords: Distal femur fractures, Locking compression plate, Neer's functional score, Muller's classification

\section{INTRODUCTION}

Distal femur fractures comprise of $6 \%$ of the fractures involving femur approximately. ${ }^{1,2}$ Bimodal age distribution is seen. Peak incidence is seen in patients below 40 years of age, commonly males, experiencing high-energy trauma. Incidence again rises in patients $>50$ years, commonly females, with osteoporosis, who experience relatively low energy trauma. Frequent mechanism of injury is axial load to femur and less frequently rotational forces lead to distal femoral fractures. ${ }^{2}$ Distal femur fractures are complex injuries that involve distal $15 \mathrm{~cm}$ of femur both supracondylar and intercondylar, whose management is an arduous task, as these have an inherent tendency for high morbidity.

The purpose of surgical management is to restore articular congruency, limb alignment and early mobilization. Impairment can nevertheless occur in fractures with considerable articular surface involvement, 
significant bone comminution, and serious soft tissue injury. ${ }^{3,4}$ Locking compression plate is the integration of compression plating, locked plating and bridge plating, causing minimal soft tissue damage and periosteal vessels are preserved. Hence it functions like a closed external fixator. $^{5}$

The objective of this study is to appraise the outcome of distal femur fractures management with locking compression plate in terms of relief of pain, regain of flexion, and return to function, residual anatomic deformity and radiographic parameters.

\section{METHODS}

This prospective study evaluated 20 patients with distal end femur fracture. All the cases were treated at Mediciti institute of medical sciences, Ghanpur, between December 2013 to December 2015 and followed for a minimum of 6 months.

The method used for fracture fixation was open reduction internal fixation or minimally invasive plate osteosynthesis with locking compression plate. All fractures in this prospective study were post-traumatic. No pathological fracture (excluding osteoporosis) was included. Fractures treated conservatively or operated with other fixation systems are not included.

The following clinico-radiological evaluation was observed for patients with fracture lower end of femur in casualty.

A detailed history is taken, to ascertain the mode of violence and to correlate the fracture pattern and to anticipate hidden complications.

Evaluation of patients in terms of: a) age b) sex c) mode of trauma d) period between injury and arrival.

Stabilization of patient with intravenous fluids, oxygen and blood transfusion as and when required. Thorough examination is done to rule out any head/chest/ abdominal/spinal or pelvic injury. In polytrauma, local examination of ipsilateral hip, knee, leg and ankle is done. Examination of involved limb is done to rule out neurovascular deficit. Limb is temporarily stabilized in Thomas splint to shift the patient for anteroposterior and lateral radiographs of affected extremity. Traction views may be helpful; 45 degree oblique views can better delineate intercondylar involvement. Radio-graphic evaluation of the entire involved lower extremity is warranted, as concomitant injuries are common. Contralateral views may help with comparison and may serve as a template for preoperative planning. In case of open fracture, thorough irrigation and lavage of associated compound injuries was done with at least 9 liters normal saline followed by dry or burn mesh dressings followed by giving I.V. antibiotics, tetanus toxoid and tetanus antitoxin (if needed). Neer's functional scoring was used to assess the outcome of surgery, for adult distal femoral fractures. ${ }^{6,7}$

\section{Patient selection}

\section{Inclusion criteria}

Inclusion criteria were patients admitted to Mediciti institute of medical sciences, Ghanpur with fracture lower end of femur fixed with LCP; all skeletal mature patients (>18years); patients with closed or Open distal femur fractures up to Gustilo - Anderson's classification type I, II and III A; patients with osteoporosis; patients willing to give consent.

\section{Exclusion criteria}

Exclusion criteria were patients with Gustillo Anderson type IIIB open fracture and Muller's OTA classification type C; patients with associated tibial plateau fractures; age of patient less than 18 years of age or open growth plate; patients managed conservatively; fractures with distal neurovascular deficit; patient with pathological fracture excluding osteoporosis; patients absent for follow-up.

\section{Implant used}

Gundrilling technique is used in manufacturing the plate and screws from $316 \mathrm{~L}$ stainless steel. Low-profile, anatomically precontoured plates with side differentiation designed for right or left femur; with distal expansion and anterior bow to match condyles and bow of shaft of the femur. LCP is available with 6 to 18 combi holes in shaft. Combi hole is a combination of locking screw hole with a dynamic compression hole, providing either locking capability or axial compression function.

\section{Preoperative investigation}

Complete blood picture, random blood sugar, renal function tests, serum electrolytes, blood group and $\mathrm{Rh}$ typing, coagulation profile, electrocardiograph, 2D $\mathrm{ECHO}$, chest $\mathrm{X}$ ray $\mathrm{PA}$ view and any additional investigations as advised by anesthetist.

\section{Surgical technique}

The involved limb from thigh to middle third leg was shaved a day before surgery. On the day of surgery lignocaine and broad spectrum cephalosporin test dose is given. Limb examined to rule out any blister formation at the operating site. 1 to 2 hour prior to surgery I.V. antibiotic was administered. Patient is placed supine on radiolucent table, after appropriate anesthesia was given, a small bolster is placed under the hip to prevent external rotation of the limb and knee is maintained in 30 degree flexion with support of rolled sheets. The limb is scrubbed, painted and draped. Through lateral approach, incision is given from distal third femur in mid-lateral 
line and curved distally towards tibial tuberosity, the skin and subcutaneous tissues, iliotibial band were cut in line, hemostasis achieved, blunt dissection done to elevate vastus lateralis from intermuscular septum anteriomedially.

Fracture site is reached; reduction of fracture fragments was achieved by manual traction with knee in flexion and temporarily stabilized with $\mathrm{K}$ wires. Reduction, restoration of limb length and alignment is confirmed under C arm guidance and fixed with locking compression plate. Surgical drain is placed and wound is closed in layers after hemostasis is achieved.

\section{Post-operative care and rehabilitation}

Patient is monitored for vitals, presence of distal pulse, and return of active toe movements. Limb is kept in elevated position. Input-output charting and drain output is recorded. I.V. antibiotics are continued for 48 hours. Rehabilitation is custom made to the patient and the fracture type.

Active and passive knee and hip Range of motion exercises are started within the first week post operatively unless not permitted by associated injuries. We advised partial weight bearing from $3^{\text {rd }}$ to $4^{\text {th }}$ week and full weight bearing after radiological evidence of healing. Both are delayed in fractures with intraarticular extension and extensive comminution.

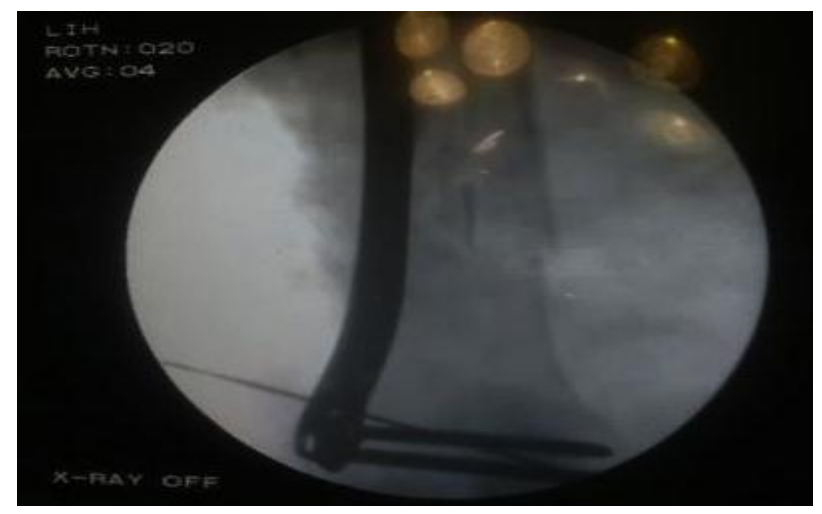

Figure 1: Intraoperative $\mathrm{C}$ arm image.

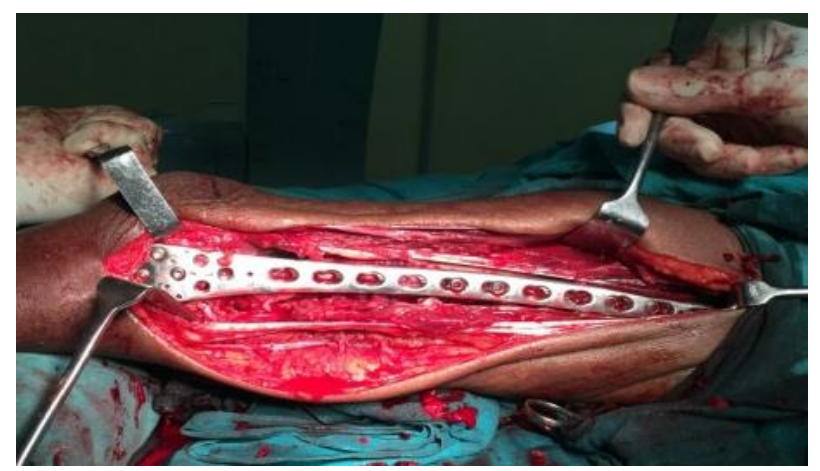

Figure 2: Intraoperative photograph of LCP fixation.

\section{Follow-up}

All patients were followed at regular intervals (i.e., once in a month for the first 3 months and once every 3 months thereafter). At each follow-up patient is assessed by Neer's functional scoring.

The statistical analysis was done using PSPP version 1.0 .1

\section{RESULTS}

In our study of 20 patients, 16 were males and 4 were females. The age of the patients ranged from 19 years to 77 years, with mean age of 48.57 years. The most common mode of injury was road traffic accident in 14 patients $(54.47 \%)$ against domestic fall in 6 patients $(45.53 \%)$.

Incidence of fracture is high in laborer $7(34.78 \%)$, employee $5(21.14 \%)$, student $2(4.71 \%)$, home maker 2 $(14.01 \%)$ and miscellaneous $4(25.36 \%)$.

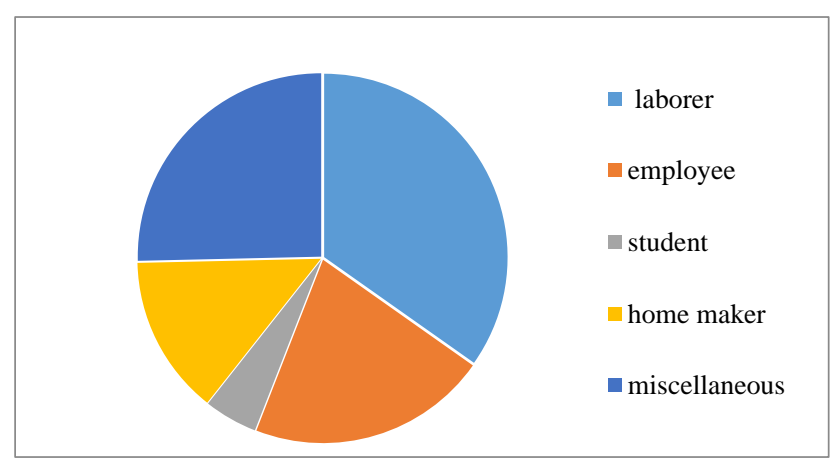

Figure 3: Distribution as per occupation.

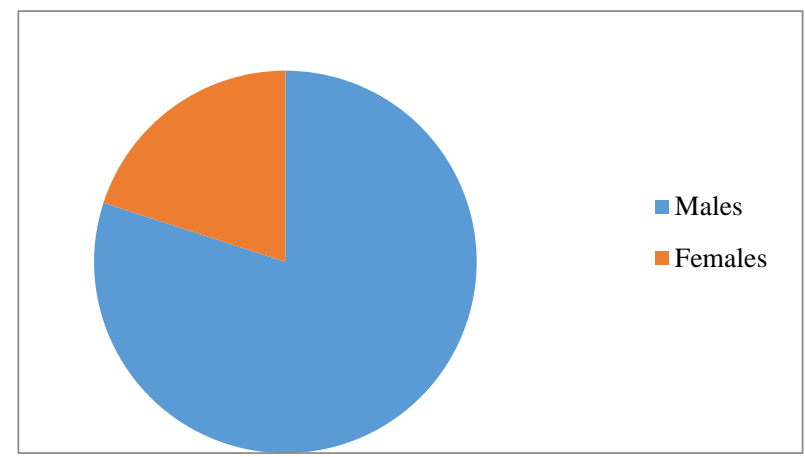

Figure 4: Sex distribution.

In our study, $14(68.84 \%)$ patients sustained injury to the right femur and $6(31.16 \%)$ patients to the left femur, showing there was right sided predominance.

17 patients were operated within one week after injury, 1 patient had been taken to a bone setter earlier and presented after about 10 days after injury. For 2 patients surgery had been delayed due to medical conditions. 
Meticulous clinical examination was made in all patients and associated injuries were treated with proper documentation.

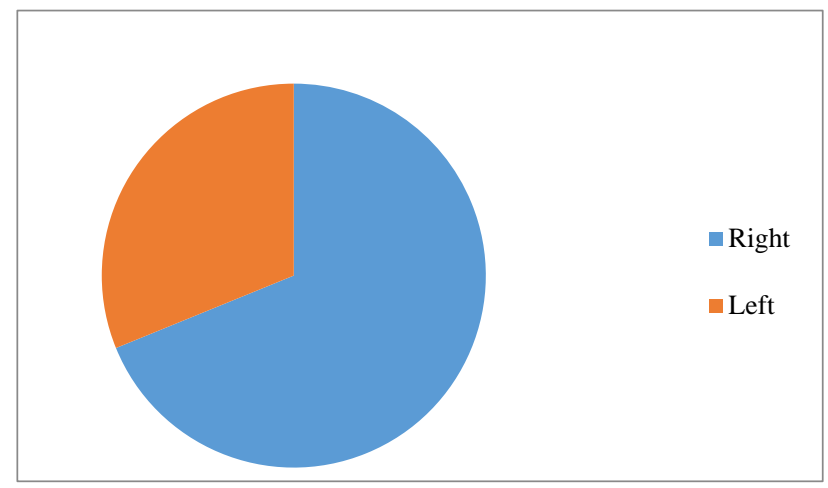

Figure 5: Side involvement.

Out of 20 cases, 4 patients had associated injuries. One had metacarpal fracture fixed with $\mathrm{k}$ wire, one had humerus shaft fracture fixed with plating and two had fracture both bones of forearm fixed with plating.

Of the 20 cases, according to Muller's classification 2 (9.90\%) fractures were of type A1, 7 (34.54\%) type A2, 1 (9.30\%) type A3, 2(11.35\%) type B2, 3 (11.71\%) type C1, $4(18.72 \%)$ type C2, $1(4.47 \%)$ were of type C3 fractures. Of the 20 cases 14 were closed fractures and 6 were open fractures. Out of 20 cases 15 (72.95\%) were operated in open reduction and internal fixation technique and $5(27.05 \%)$ through minimally invasive technique.

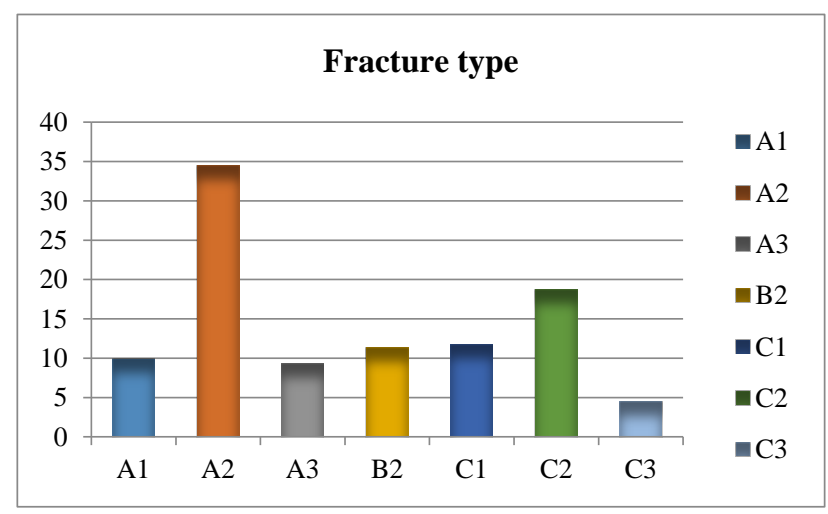

Figure 6: Frequency of fracture type incidence.

\section{Complications}

Early complications were encountered in 3 patients and these were superficial wound infection, wound gaping. Late complications were observed like mal-union with varus in 1 patient, Plate breakage in 1 patient, knee stiffness in 1 patient.

When evaluated for pain, 9 of 20 patients had no pain (45\%), 8 patients had intermittent pain due to knee stiffness $(40 \%), 3$ patient had pain with fatigue. $(15 \%)$. When evaluated for function, in our study, 4 out of
$20(20 \%)$ patients were able to return to their function as before injury. Mild restriction was noted in rest of 13 $(65 \%)$ patients, restriction with stair climbing in $3(15 \%)$ patients. In our observation, 7 out of $20(35 \%)$ patients gained knee flexion of $135^{\circ}$ or normal, $9(45 \%)$ patients gained upto $100^{\circ}$ and Remaining 4 patients regained a knee flexion upto $80^{\circ}$. In our observation, 6 (30\%) patients worked as before injury, $10(50 \%)$ patients with mild handicap and $4(20 \%)$ patients shifted to alter work.

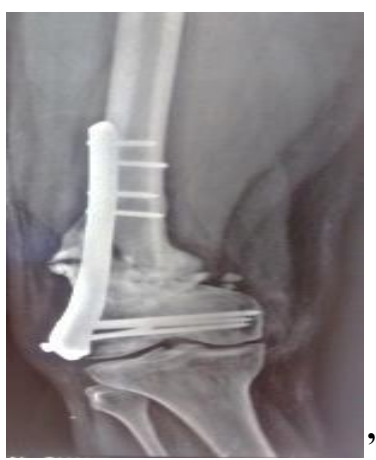

Figure 7: Radiograph showing varus collapse.

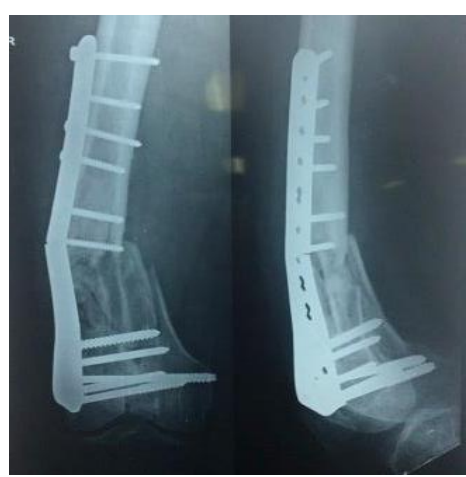

Figure 8: Radiograph showing implant breakage.

In our study when gross anatomy was analysed, $6(30 \%)$ patients developed mild varus angulation of $10^{\circ}$ and another 7 (30\%) patients had $5 \mathrm{~mm}$ shortening, and the remaining $7(35 \%)$ patients had thickening only. In follow-up radiographs, out of 20,4 patients $(20 \%)$ had near normal radiographs, $10(50 \%)$ had 5 degrees angulation, another $5(25 \%)$ patient had $10 \mathrm{~mm}$ displacement and 1 patient had 15 degree angulation.

Table 1: Grading of outcome as per Neer's score overall rating.

\begin{tabular}{|lll|}
\hline Excellent & Above 85 units & $\mathbf{6}$ \\
\hline Good & $70-85$ units & 9 \\
\hline Fair & 55-69 units & 5 \\
\hline Poor & Below 55 units & 0 \\
\hline
\end{tabular}

Overall results were excellent in $6(23.31 \%)$ out of 20 cases and were good in $9(54.11 \%)$ cases and $5(22.58 \%)$ had a fair result. The overall mean Neer's score in our study was 81.17 . 


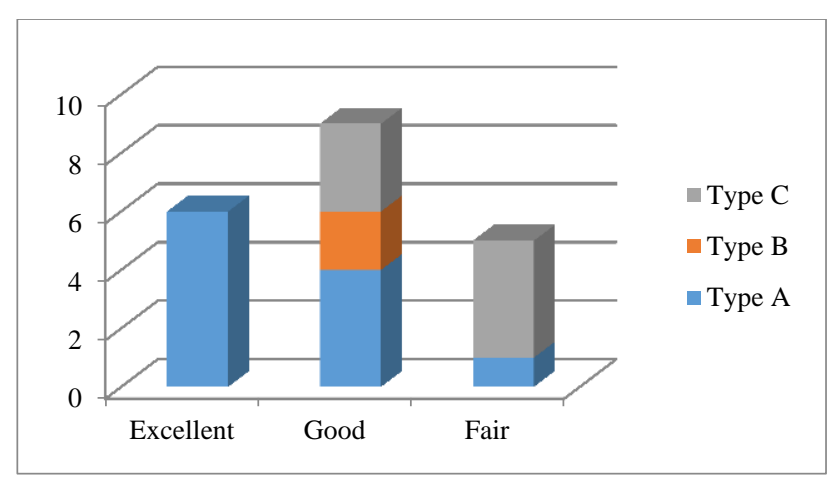

Figure 9: Fracture type vs. outcome as per Neer's score.

\section{DISCUSSION}

Distal femur fractures have been documented as hard to treat as they are unstable due to the pull of the distal fragment by the muscles. These fractures often have a potential for long term disability and potential to develop infection. Our study comprised of 20 patients with distal femur fractures who were treated by locking compression plate (LCP) using open reduction (ORIF), and minimally invasive (MIPPO) technique when appropriate. The final outcome was determined in terms of pain relief, regaining the lost knee function, anatomical and radiological outcome using Neer's score and compared with other studies.

In our study, sample size is 20 which is comparable to study of LCP by Markmiller et al, Weight et al as opposed to 103 in Kregor et al and 109 in Gaines et al. ${ }^{8-11}$

In our study $76.69 \%$ were males. The mean age was 48.57years (range 19 to 77 years). Mode of injury was domestic fall in $45.53 \%$ patients against road traffic accidents in $54.47 \%$ of patients. Domestic fall was the most common cause of injury for distal femur fractures in elderly females. We found a right sided preponderance in our study with $68.84 \%$ of right sided and $31.16 \%$ of left sided involvement. The average range of flexion achieved was about $109^{\circ}$.

Muller's comprehensive classification system was used to classify the fractures, type A (53.74\%) and C (34.9\%) account for most of the fractures. The good outcome seen in our study can be attributed to more of type A fractures $(53.74 \%)$, which usually show favorable results. we had only $10 \%$ of open fractures. And the small sample size can be used only as Level III evidence in Evidence based medicine.

We had one case of varus collapse due to gross communition. One case had an implant failure (Plate breakage) due to early weight bearing. Cases needing hardware revision is $5 \%$ comparable to Kayali et al study at $4 \%$ as opposed to $20 \%$ in Fankhauser et al and Vallier et al. ${ }^{12-14}$
In our study we had no nonunion which is comparable to Fankhauser et al, Weight et al, Kayali et al..$^{9,12,13}$ In our study, there is no delayed union was seen which is comparable to Markmiller et al, Weight et al as opposed to $12 \%$ in Schutz et al, $15 \%$ in Vallier et al. ${ }^{8,9,14,15}$

Locking compression plate outcomes are favourable in osteoporotic bone and in fractures associated with marked comminution due to rigidity of plate screw construct. ${ }^{16}$ The locking compression plate offer multiple points of fixed plate to screws contact, create greater stability and thereby minimize the susceptibility of varus collapse. ${ }^{17}$

In our study, radiological union was seen at an average of 16 weeks which is comparable to study of LCP by Kayali et al in 2005, which averages 15 weeks. Overall results were excellent in 6 out of 21 cases and 9 were good and fair in remaining 5 cases. The overall average Neer's score in our study was 81.17 , in contrast with 67.7 by Schandelmaier et al. ${ }^{18}$

We can opine that all the excellent results were from type A fracture and good results were seen in type A, B, C and fair results seen in type $\mathrm{C}$ and $\mathrm{A}$. The difficulty in managing distal femoral fractures with osteoporosis, extensive comminution and revision surgeries following failed implant can be addressed effectively using locking condylar plate. ${ }^{17} \mathrm{We}$ assume that locking plates are an effective improvement in fracture management. Yet the deficiencies of this new technology and indications for its use have not been completely elucidated and the longterm results are awaited.

Nevertheless, locking compression plates can break when physiological loads are external to plate-design parameters. ${ }^{19}$ The locked screws can loosen from the plate consequential to failure of the screw to seat into the plate congrously, as a result of cross-threading or when insufficient screw torque is used to engage the screw threads into the plate threads. ${ }^{19}$

\section{CONCLUSION}

The LCP condylar plate is the treatment of choice in the management of distal femoral fractures especially type A fractures where we have found higher Neer's scores. The use of LCP decreases the chances of implant failure and screw backing out. Early passive mobilization of the knee is possible due to stable fixation even in osteoporotic fractures. Aim must be to achieve length, axis and rotation by maintaining the biology at fracture site. LCPs do not provide compression of the fracture fragments hence locked screws should be tightened after adequate reduction or after lag screw to provide compression. Intraoperatively restoration of both medial and lateral column of femur is necessary to prevent complications.

Funding: No funding sources Conflict of interest: None declared

Ethical approval: The study was approved by the institutional ethics committee 


\section{REFERENCES}

1. Kolmert L, Wulff K. Epidemiology and treatment of distal femoral fractures in adults. Acta Orthop. Scand. 1982;53:957-62.

2. Martinet O, Cordey J, Harder Y, Maier A, Buhler M, Barraud GE. The epidemiology of fractures of the distal femur. Injury. 2000;31(3):62-3.

3. Sanders R, Swiontowski. Double plating of comminuted unstable fractures of distal part of femur. JBJS. 1991;730:341-5.

4. Schatzker J. Fractures of the distal femur revisited. Clin Orthop Relat Res. 1998;347:43-56.

5. Kregor PJ, Stannard J, Zlowodzki M, Cole PA, Alonso J. Distal femoral fracture fixation utilizing the Less Invasive Stabilization System (L.I.S.S.): the technique and early results. Injury. 2001;32:3247.

6. Neer CS II, Grantham SA, Shelton ML. Supracondylar Fracture of the Adult Femur - A Study of One Hundered and Ten Cases. JBJS Am. 1967;49(4):591-613.

7. Henderson CE, Kuhl LL, Fitzpatrick DC. Healing Complications Are Common After Locked Plating for Distal Femur Fractures. Clin orthop Relat Res. 2011;469:1757-65.

8. Markmiller M, Konrad G, Sudkamp N. Femur-LISS and distal femur nail for fixation of distal femoral fractures. Clin Orthop and Relat Res. 2004;426:2527.

9. Weight M, Collinge C. Early results of the less invasive stabilization system for mechanically unstable fractures of the distal femur. J Orthop Trauma. 2004;18:503-8.

10. Kregor PJ, Stannard J, Zlowodzki M, Cole PA, Alonso J. Distal femoral fracture fixation utilizing the Less Invasive Stabilization System (L.I.S.S.): The technique and early results. Injury. 2001;32(3):32-47.

11. Gaines RJ, Sanders R, Sagi HC, Haidukewych GJ. Titanium versus stainless steel locked plates for distal femur fractures: is there any difference? OTA abstract. 2008;55:8.
12. Kayali C, Agus H, Turgut A. Successful results of minimally invasive surgery for comminuted supracondylar femoral fractures with LISS: comparative study of multiply injured and isolated femoral fractures. J Orthop Sci. 2007;12:458-65.

13. Fankhauser F, Gruber G, Schippinger G, Boldin C, Hofer HP, Grechenig W, et al. Minimal-invasive treatment of distal femoral fractures with the LISS (Less Invasive Stabilization System): a prospective study of 30 fractures with a follow up of 20 months. Acta Orthop Scand. 2004;75(1):56-60.

14. Vallier HA, Hennessey TA, Sontich JK, Patterson BM. Failure of LCP condylar plate fixation in the distal part of the femur-A report of six cases. J Bone J Surg Am. 2006;88(4):846- 53.

15. Schutz M, Muller M, Krettek C, Hontzsch D, Regazzoni P, Ganz R, et al. Minimally invasive fracture stabilization of distal femoral fractures with the LISS: a prospective multicenter study. Results of a clinical study with special emphasis on difficult cases. Injury. 2001;32(3):48-54.

16. Egol KA, Kubiak EN, Fulkerson E, Kummer FJ, Koval KJ. Biomechanics of locked plates and screws. J Orthop Trauma. 2004;18(8):488-93.

17. Zlowodzki M, Bhandari M, Marek DJ, Cole PA, Kregor PJ. Operative treatment of acute distal femur fractures: systematic review of 2 comparative studies and 45 case series (1989 to 2005). J Orthop Trauma. 2006;20(5):366-71.

18. Schandelmaier P, Partenheimer A, Koenemann B, Grun OA, Krettek C. Distal femoral fractures and LISS stabilization. Injury. 2001;32 (3):55-63.

19. Sommer C, Babst R, Muller M, Hanson B. Locking Compression Plate Loosening and Plate Breakage A Report of Four Cases. J Orthop Trauma. 2004;18(8):571-7.

Cite this article as: Konuganti SR, Jakinapally SR, Rao VP, Rapur S. Management of distal femur fractures with locking compression plate: a prospective study. Int J Res Orthop 2018;4:208-13. 